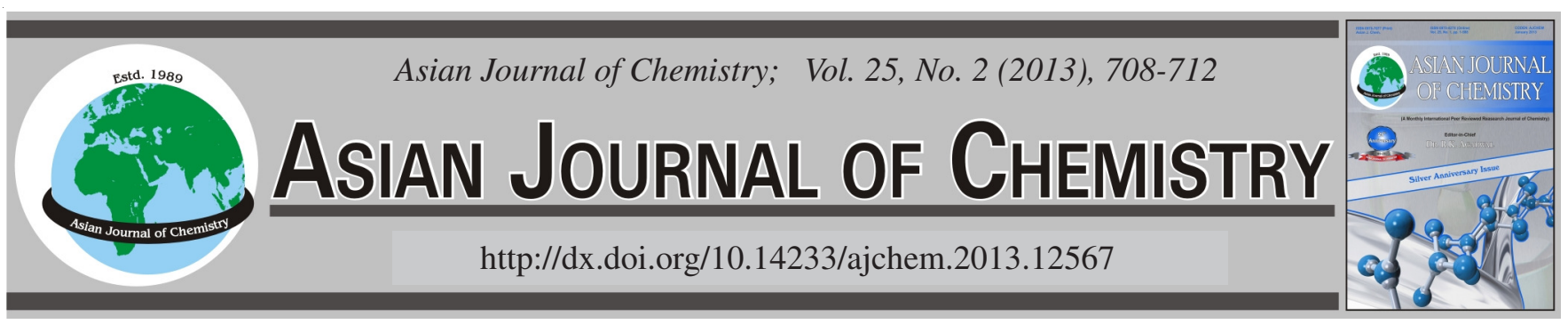

\title{
A Novel Method for Metal-Activated Carbon Particle Production and Adsorption Effects of Harmful Gas
}

Won-Chun OH ${ }^{1, *}$, Jong-Gyu Kim² ${ }^{2}$, Hyuk Kim² ${ }^{2}$ Lei Zhu ${ }^{1}$, Chong-Yeon Park ${ }^{1}$, Jong-Geun Choi ${ }^{1}$, Trisha Ghosh ${ }^{1}$ and Ze-Da Meng ${ }^{1}$

${ }^{1}$ Department of Advanced Materials \& Science Engineering, Hanseo University, Seosan-si, Chungnam-do, 356-706, South Korea ${ }^{2}$ Hanil Green Tech Co. Ltd., Buyeo-gun, Chungnam-do, 323-82, South Korea

*Corresponding author: Fax: +82 41 6883352; Tel: +82 41 6601337; E-mail: wc_oh@hanseo.ac.kr

(Received: 12 August 2011;

Accepted: 14 August 2012)

AJC-11961

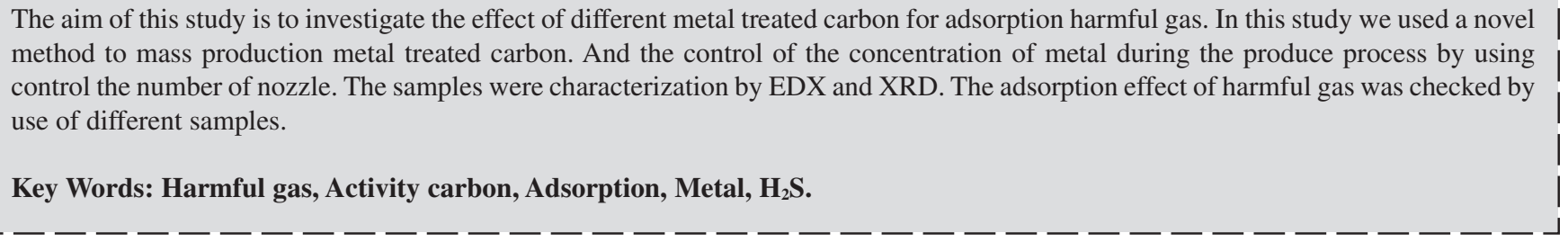

\section{INTRODUCTION}

Nowadays, the environmental practices are paying more and more attention on providing green product while the pollutants are being removed and controlled for competitive advantages sustainable development ${ }^{1-3}$. Ammonia, hydrogen sulfide and $n$-butane can represent hazardous or harmful substances. For example $\mathrm{H}_{2} \mathrm{~S}$ is an odor gas that causes life threatening at higher concentration (500 ppm). It is well known that $\mathrm{H}_{2} \mathrm{~S}$ might be produced from power plants, natural gas, crude oil and industrial streams ${ }^{4,5}$. The effective trapping of these compounds in the pores of mesoporous and microporous adsorbents represents a straightforward option to reduce the presence of these substances in the environment ${ }^{6,7}$.

Activated carbons (AC) are widely used in gas purification, solvent recovery, waste water treatment, etc. It is recognized that the pore structure is the most important property of activated carbons for their application in adsorption processes ${ }^{8}$. Activated carbon are manufactured by the pyrolysis of carbonaceous materials of vegetable origin, such as wood, coal, peat, fruit stones and shells, or synthetic polymers such as viscose rayon, PAN, or phenolics, followed by activation of the chars obtained from them. Activated carbons have a wide range of pore sizes, from the Angstrom scale of micropores to the micrometer scale of macropores. They are used in various applications depending on their porous properties. For example, activated carbons with many micropores are used for gas adsorption, mesopores are necessary for the adsorption of large molecules, etc., their content of acidic and basic surface sites ${ }^{9-11}$ and the presence of suitable metallic derivatives ${ }^{12}$ can favour the process of adsorption of certain gaseous chemical compounds.

Certain metallic components present in the ashes of the active carbons can also play an important role; e.g., iron in the ashes is reported to favour harmful gas sorption ${ }^{13}$. Moreover, some authors have reported that the addition of certain cations to active carbons improves the efficiency of harmful gas sorption $^{14-18}$. In more detail, it has been observed that the presence of vanadium, iron and some other transition group metals on the activated carbons promotes an increase in the quantity of harmful gas adsorbed from gaseous mixtures.

Many investigations have been performed to explore novel raw materials (such as waste materials) and to optimize the preparation conditions to obtain activated carbons with the desired porous properties. Optimization of the activation process has been extensively investigated ${ }^{19-24}$. This paper reports a novel method for metal activation activated carbon. This method is better than normal method, which can economize more reagents and have better effect for removal of gas. Granular activated carbons were loaded with metals $\left(\mathrm{CuSO}_{4} \cdot \mathrm{H}_{2} \mathrm{O}, \mathrm{AgNO}_{3}\right.$, $\mathrm{CoCl}_{2} \cdot 6 \mathrm{H}_{2} \mathrm{O}, \mathrm{KOH}$ and $\mathrm{H}_{2} \mathrm{PO}_{4}$ ) to act as adsorbents for ammonia, sulfureted hydrogen and $n$-butane adsorption at ambient temperature. During the manufacturing process, samples at various stages were produced and their performance for removing different harmful gas was compared.

\section{EXPERIMENTAL}

Granular activated carbon (size: $2-3 \mathrm{~mm}$ ) as starting material. Different metal salt solution $\mathrm{CuSO}_{4} \cdot \mathrm{H}_{2} \mathrm{O}, \mathrm{AgNO}_{3}$, 
$\mathrm{CoCl}_{2} \cdot 6 \mathrm{H}_{2} \mathrm{O}, \mathrm{KOH}$ and $\mathrm{H}_{2} \mathrm{PO}_{4}$ are used as metal sources. $\mathrm{CuSO}_{4} \cdot \mathrm{H}_{2} \mathrm{O}, \mathrm{AgNO}_{3}$ and $\mathrm{KOH}$ were obtained from Duksan Pure Chemicals Co. Ltd. Korea. $\mathrm{CoCl}_{2} \cdot 6 \mathrm{H}_{2} \mathrm{O}$ and $\mathrm{H}_{2} \mathrm{PO}_{4}$ were obtained from Daejung Chemicals and Metals Co. Ltd. Korea.

Treatment with metals: In this experiment, we used granular activated carbon (size: $2-3 \mathrm{~mm}$ ) as starting material. Different metal salt solution $\mathrm{CuSO}_{4} \cdot \mathrm{H}_{2} \mathrm{O}, \mathrm{AgNO}_{3}, \mathrm{CoCl}_{2} \cdot 6 \mathrm{H}_{2} \mathrm{O}$, $\mathrm{KOH}$ and $\mathrm{H}_{3} \mathrm{PO}_{4}$ are used as metal sources. 0.3 M metal salt solutions are prepared by dissolved in water as solvent. Table-1 is nomen-clature of the samples prepared with the photocatalysts.

\begin{tabular}{|c|c|}
\hline \multicolumn{2}{|c|}{$\begin{array}{c}\text { TABLE-1 } \\
\text { NOMENCLATURE OF THE SAMPLES PREPARED } \\
\text { WITH THE PHOTOCATALYSTS }\end{array}$} \\
\hline Preparation method & Nomenclatures \\
\hline $0.3 \mathrm{M} \mathrm{KOH}+100 \mathrm{~g} \mathrm{AC}$ & $\mathrm{Ag}-\mathrm{AC}$ \\
\hline $0.3 \mathrm{M} \mathrm{AgNO}_{3}+100 \mathrm{~g} \mathrm{AC}$ & $\mathrm{Ag}-\mathrm{AC}$ \\
\hline $0.3 \mathrm{M} \mathrm{CuSO}_{4} \cdot \mathrm{H}_{2} \mathrm{O}+100 \mathrm{~g} \mathrm{AC}$ & $\mathrm{Cu}-\mathrm{AC}$ \\
\hline $0.3 \mathrm{M} \mathrm{CoCl}_{2} \cdot 6 \mathrm{H}_{2} \mathrm{O}+100 \mathrm{~g} \mathrm{AC}$ & Co-AC \\
\hline $0.3 \mathrm{M} \mathrm{H}_{2} \mathrm{PO}_{4}+100 \mathrm{~g} \mathrm{AC}$ & $\mathrm{P}-\mathrm{AC}$ \\
\hline
\end{tabular}

$\mathrm{AC}=$ Activated carbon

The experiment installation are shown in Fig. 1, (a) is the carbon particles flux control valve, which can control the quantity of carbon particles; (b) is the inlet tube; (c) is the control valve for control the flow rate of metal salt solution; (d) is the reaction tube for carbon particles fall and the solution will cling on the carbon; (e) is the spray-pipe system and (f) is the nozzle. During this experiment we use (a) to control the flow rate of carbon particles and use (c) to control the nozzle number in order to control the flow rate of metal salt solution. The flow rate of carbon particles is $100 \mathrm{~g} / \mathrm{min}$. As shown in Fig. 2, the flow rate is increased from $50-170 \mathrm{~mL} / \mathrm{min}$ by increasing the nozzle number increased from 1-3.

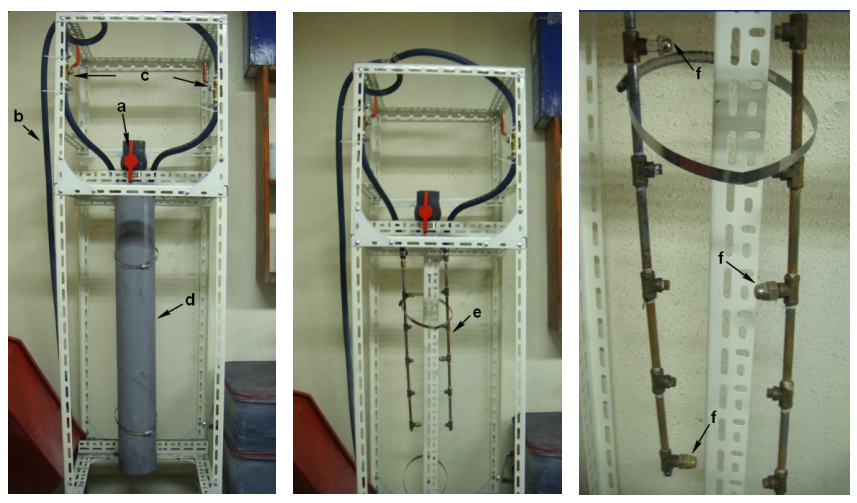

Fig. 1. Experiment installation for produce metal treated carbon (a) is the carbon particles flux control valve; (b) is the inlet tube; (c) is the control valve; (d) is the reaction tube; (e) is the spray-pipe system; (f) is the nozzle

In this experiment we used different nozzle number and different processing mode to preparation of samples. At stage (a) we obtain only the activated carbon without metal sale solution during the fall process; at stage (b), we obtain the activated carbon and metal sale solution together during the fall process. After mixed for $0.5 \mathrm{~h}$, the samples are dried at $100{ }^{\circ} \mathrm{C}$.

Characterization of activated carbons: XRD (Shimadzu XD-D1, Japan) result was used to identify the crystallinity with monochromatic high-intensity $\mathrm{CuK}_{\alpha}$ radiation $(\lambda=1.5406$

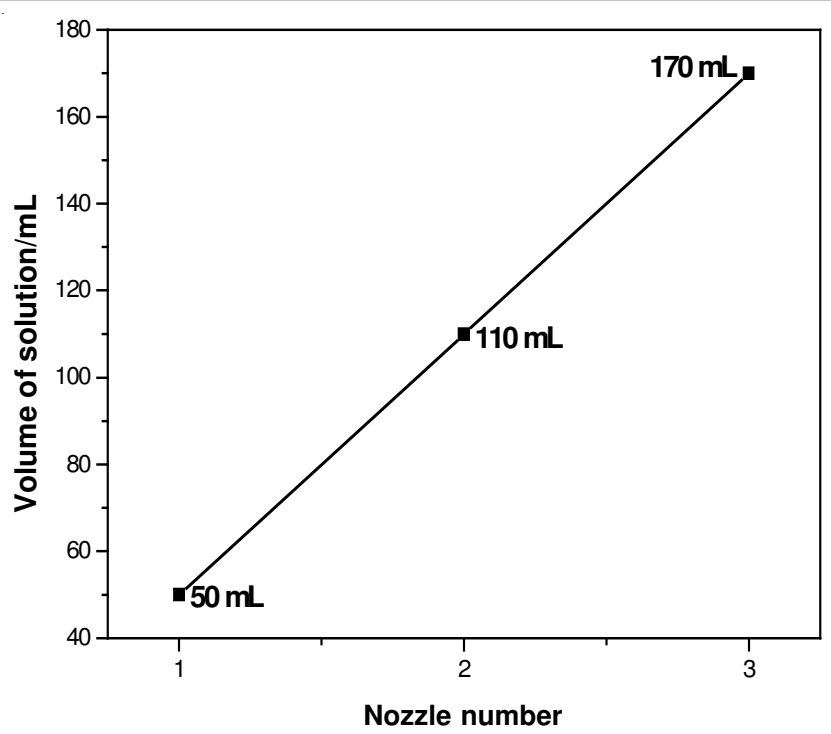

Fig. 2. Volume of solution for different nozzle number

$\AA$ ). The element mapping over the desired region of prepared composite was detected by an EDX analysis.

Harmful gas adsorption: The harmful gas adsorption measurements on the different carbon samples were carried out using a fixed bed system. One gram of carbon is placed on top of a layer of quartz wool inside a vertical quartz pipe (inner diameter $15 \mathrm{~mm}$ ). In each experiment, a total of $5 \mathrm{~g}$ of adsorbents was packed into it. The pipe is inserted in an electrically heated cylindrical oven, electronically controlled to hold the temperature constant at $100{ }^{\circ} \mathrm{C}\left( \pm 1^{\circ} \mathrm{C}\right)$. Different compositions of the gaseous sorption mixture were passed for $2 \mathrm{~h}$ through the carbon fixed bed (with a flow of $100 \mathrm{~mL} /$ min). The gas compositions used were as follow: (a) $\mathrm{NH}_{3}(20 \%)$ and $\mathrm{N}_{2}(80 \%)$; (b) $\mathrm{H}_{2} \mathrm{~S}(20 \%)$ and $\mathrm{N}_{2}(80 \%)$ and (c) $n$-butane $(20 \%)$ and $\mathrm{N}_{2}(80 \%)$. The amount of $\mathrm{SO}_{2}$ adsorbed onto the samples was detected using a desorption process carried out at $360{ }^{\circ} \mathrm{C}$. Fig. 3 is the adsorption plant, (a) is the quartz tube (b) is the experimental facilities for adsorption.

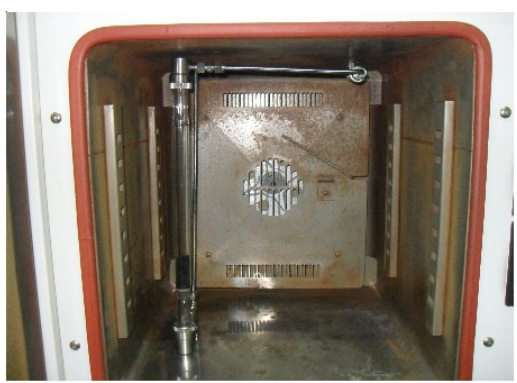

(a)

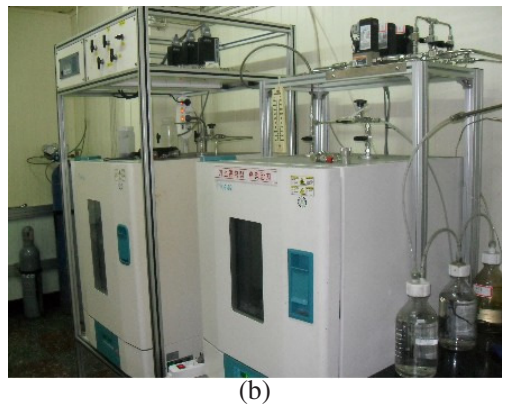

Fig. 3. Gas adsorption apparatus 


\section{RESULTS AND DISCUSSION}

Fig. 4 is the XRD results for samples. The curve (a) is the XRD patterns of K-AC, the peak at $43.772 \theta$ were assigned to the (103) plan of carbon. The curve (b) is the XRD patterns of $\mathrm{Ag}$-AC, the peaks at 22.71 and $43.772 \theta$ were assigned to the (120) and (103) plans of carbon, the peaks at 38.09 and 44.28 $2 \theta$ were assigned to the (111) and (200) plans of silver. The curve (c) is the XRD patterns of $\mathrm{Cu}-\mathrm{AC}$, the peak at $43.352 \theta$ were assigned to the (111) plan of copper. The curve (d) is the XRD patterns of Co-AC, the peak at $46.092 \theta$ were assigned to the (220) plan of cobalt.

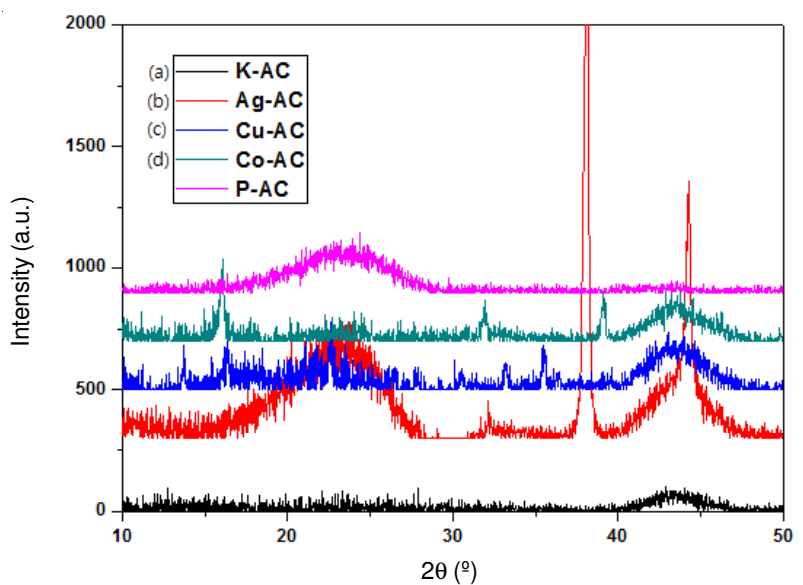

Fig. 4. XRD results for different samples

Results for use one nozzle: Fig. 5 is the EDX results for samples, before and after mixing. The molar concentrations of all metal salt solution is the same, because of the metal molecules has different atomic weight, so the EDX results for different metal treated activity carbon particles are not alike. Compare these figures it is observed when after mixing, the metallic content is increased. Before mixing the content of $\mathrm{Ag}$ is the largest, when after mixing the content of Co is largest. The content of Co-AC has the biggest change in value.

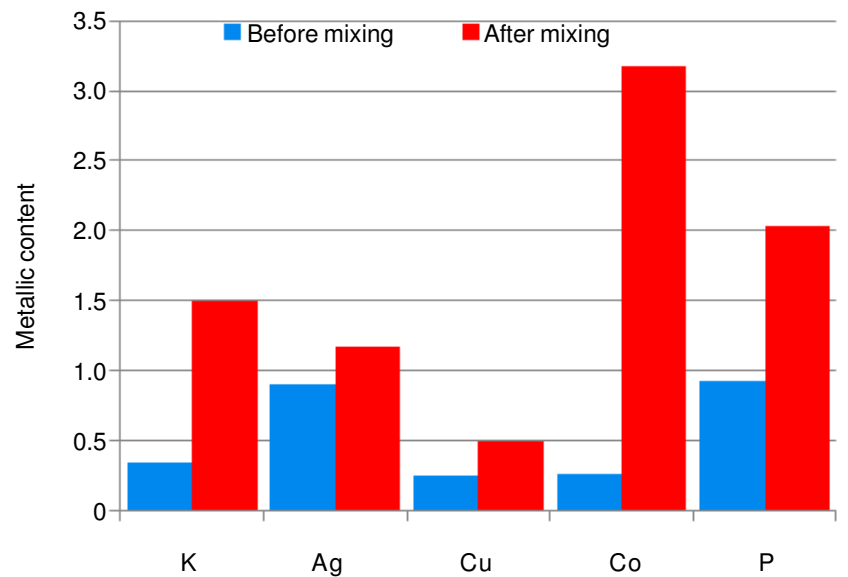

Fig. 5. EDX results for different samples; one nozzle before and after mixing

Adsorption effect for $\mathbf{N H}_{3}$ : Fig. 6 shows the remove of $\mathrm{NH}_{3}$ for samples before and after mixing which is use one nozzle during the produce process. From Fig. 6 we can see, before mixing, the adsorption effect for $\mathrm{NH}_{3}$ of samples is

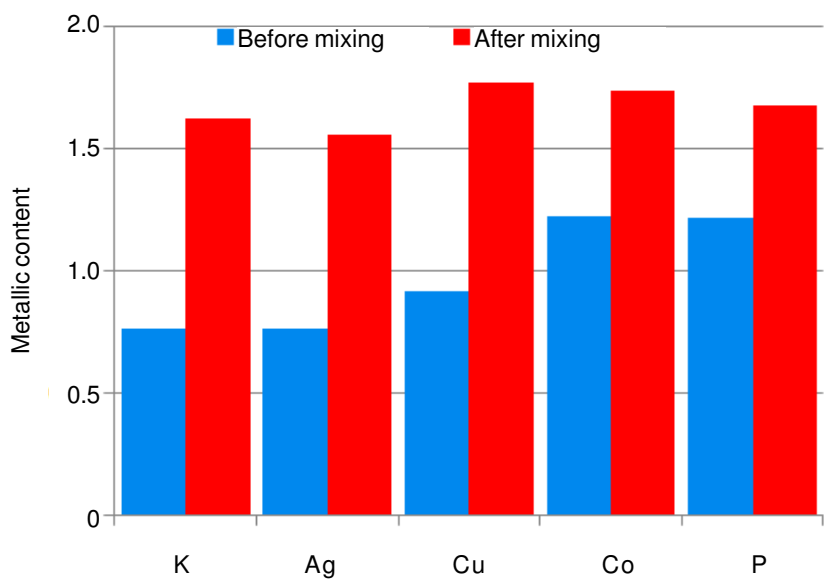

Fig. 6. Removal of $\mathrm{NH}_{3}$ for different samples; one nozzle before and after mixing

K-AC: 0.762, Ag-AC: 0.762, Cu-AC: 0.914, Co-AC: 1.219 and P-AC: 1.217 , respectively. When after mixing, the adsorption effect for $\mathrm{NH}_{3}$ of samples is K-AC: 1.623 , Ag-AC: 1.557 , $\mathrm{Cu}-\mathrm{AC}: 1.765$, Co-AC: 1.734 and P-AC: 1.676, respectively. After mixing $\mathrm{Co}-\mathrm{AC}$ has the best adsorption effect. Compare the change before and after mixing, $\mathrm{K}$-AC has the biggest change which is increased $112.99 \%$.

It is seen that during the produce process, mixing the samples can enhance the adsorption effect. This is because after mixing the samples, the content of metal molecules is increased (we can find from EDX results) ${ }^{25-28}$.

Adsorption effect for $\mathbf{H}_{2} \mathrm{~S}$ : Fig. 7 shows the removal of $\mathrm{H}_{2} \mathrm{~S}$ for samples before and after mixing which is use one nozzle during the produce process. Fig. 7 showed that before mixing, the adsorption effect for $\mathrm{H}_{2} \mathrm{~S}$ of samples is $\mathrm{K}-\mathrm{AC}$ : 2.735, Ag-AC: 2.002, Cu-AC: 2.428, Co-AC: 1.822 and P-AC: 2.563 , respectively. When after mixing, the adsorption effect for $\mathrm{H}_{2} \mathrm{~S}$ of samples is K-AC: $2.127, \mathrm{Ag}-\mathrm{AC}: 2.519, \mathrm{Cu}-\mathrm{AC}$ : 2.431, Co-AC: 1.519 and P-AC: 2.534, respectively. Before mixing $\mathrm{K}-\mathrm{AC}$ has the best adsorption effect. After mixing P-AC has the best adsorption effect. Compare the change before and after mixing, $\mathrm{Ag}-\mathrm{AC}$ has the biggest change which is increased $25.82 \%$. It is suggested that during the produce process, mixing of the samples can enhance the adsorption effect.

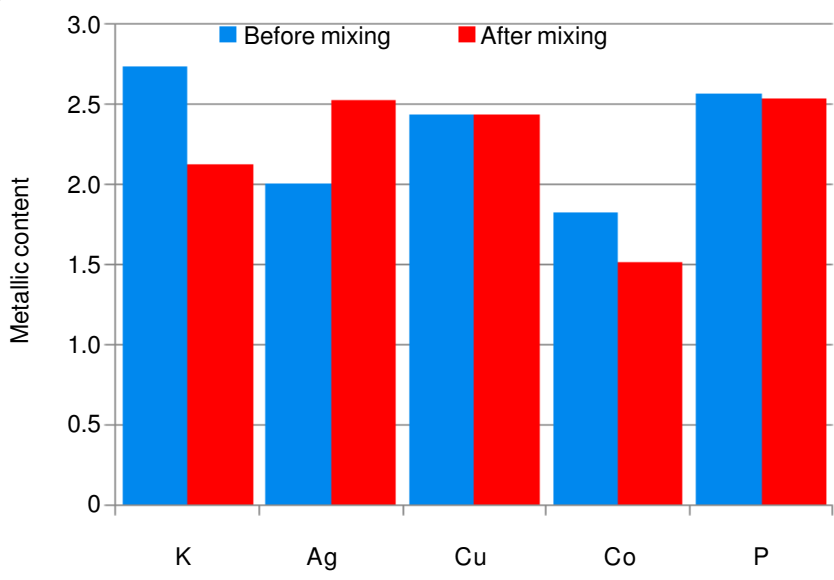

Fig. 7. Removal of $\mathrm{H}_{2} \mathrm{~S}$ for different samples; one nozzle before and after mixing 
Adsorption effect for $\boldsymbol{n}$-butane: Fig. 8 shows the removal of $n$-butane for samples before and after mixing which is use one nozzle during the produce process. Fig. 8 showed that before mixing, the adsorption effect for $n$-butane of samples is $\mathrm{K}-\mathrm{AC}: 26.5, \mathrm{Ag}-\mathrm{AC}: 26.8, \mathrm{Cu}-\mathrm{AC}: 25.4, \mathrm{Co}-\mathrm{AC}: 27.6$ and P-AC: 28.9 , respectively. When after mixing, the adsorption effect for $n$-butane of samples is K-AC: 26.9, Ag-AC: 27.2, Cu-AC: 26.8, Co-AC: 28.8 and P-AC: 29.1, respectively. Before mixing P-AC has the best adsorption effect. After mixing $\mathrm{P}-\mathrm{AC}$ has the best adsorption effect. Compare the change before and after mixing, $\mathrm{Cu}$-AC has the biggest change which is increased $0.51 \%$.

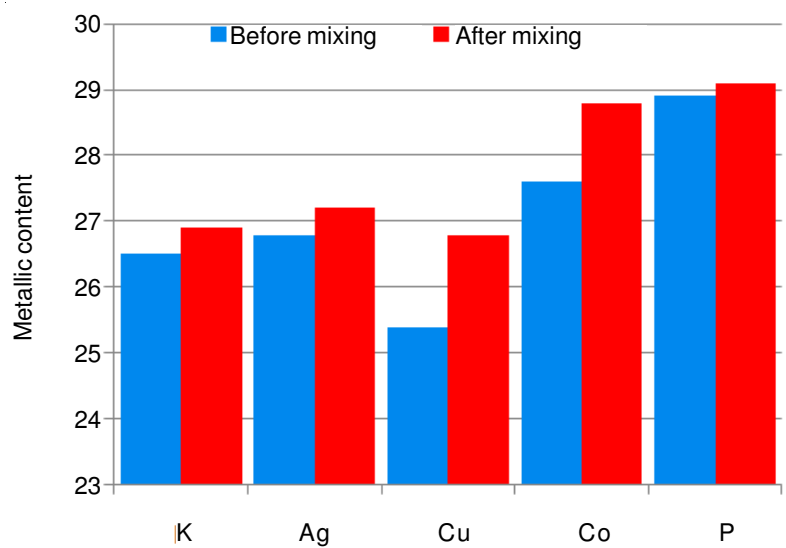

Fig. 8. Removal of $n$-butane for different samples; one nozzle before and after mixing

Results for use of three nozzles: Fig. 9 showed that the molar concentrations of all metal salt solution is the same, because of the metal molecules has different atomic weight, so the EDX results for different metal treated activity carbon particles are not alike. Compare these figures we can see when after mixing, the metallic content is increased. Compare this data to use one nozzle, it is suggested that during the produce process, the use of three nozzles can increase the content of metal. The content of $\mathrm{Co}-\mathrm{AC}$ has the biggest change in value.

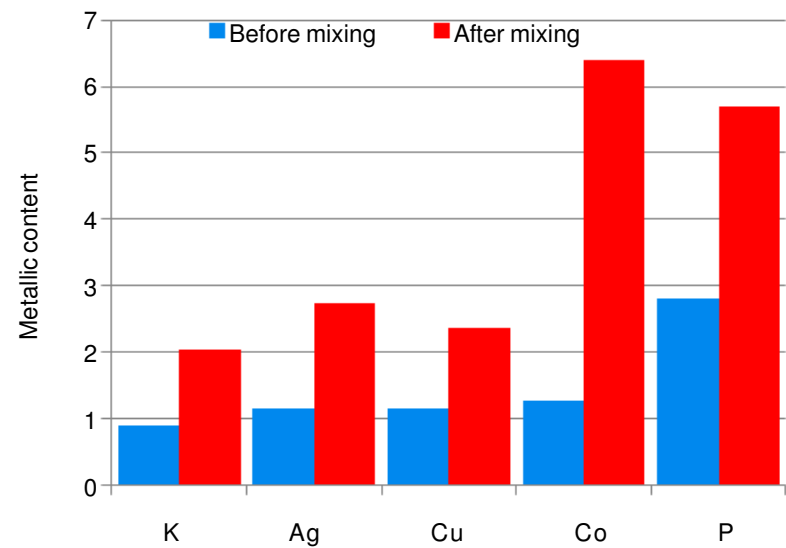

Fig. 9. EDX results for different samples; three nozzles before and after mixing

Adsorption effect for $\mathbf{N H}_{3}$ : Fig. 10 showed the removal of $\mathrm{NH}_{3}$ for samples before and after mixing which is use one nozzle during the produce process. From Fig. 10, it is clear

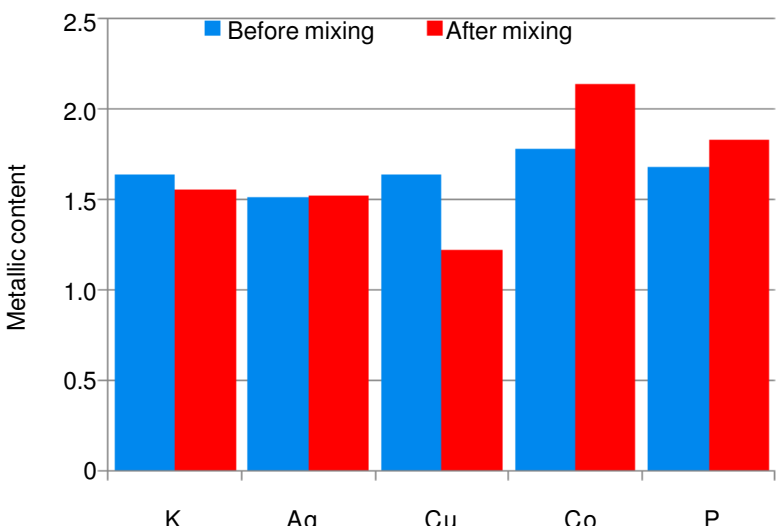

Fig. 10. Removal of $\mathrm{NH}_{3}$ for different samples; three nozzles before and after mixing

that before mixing, the adsorption effect for $\mathrm{NH}_{3}$ of samples is $\mathrm{K}-\mathrm{AC}: 1.634, \mathrm{Ag}-\mathrm{AC}: 1.512, \mathrm{Cu}-\mathrm{AC}: 1.634, \mathrm{Co}-\mathrm{AC}: 1.778$ and P-AC: 1.675 , respectively. When after mixing, the adsorption effect for $\mathrm{NH}_{3}$ of samples is $\mathrm{K}-\mathrm{AC}: 1.550, \mathrm{Ag}-\mathrm{AC}: 1.523$, $\mathrm{Cu}-\mathrm{AC}: 1.219$, Co-AC: 2.131 and P-AC: 1.828, respectively. $\mathrm{Co}-\mathrm{AC}$ has the best adsorption effect. Compare the change before and after mixing, $\mathrm{Cu}-\mathrm{AC}$ has the biggest change which is increased $19.85 \%$.

Adsorption effect for $\mathbf{H}_{2} \mathrm{~S}$ : Fig. 11 shows the removal of $\mathrm{H}_{2} \mathrm{~S}$ for samples before and after mixing which is use one nozzle during the produce process. From Fig. 11, it is observed that before mixing, the adsorption effect for $\mathrm{H}_{2} \mathrm{~S}$ of samples is K-AC: 2.126, Ag-AC: 2.567, Cu-AC: 2.512, Co-AC: 2.769 and P-AC: 2.734 , respectively. After mixing, the adsorption effect for $\mathrm{H}_{2} \mathrm{~S}$ of samples is K-AC: 2.632, Ag-AC: 2.541 , Cu-AC: 2.657, Co-AC: 2.743 and P-AC: 2.834, respectively. $\mathrm{P}-\mathrm{AC}$ has the best adsorption effect. Compare the change before and after mixing, $\mathrm{K}-\mathrm{AC}$ has the biggest change which is increased $23.80 \%$.

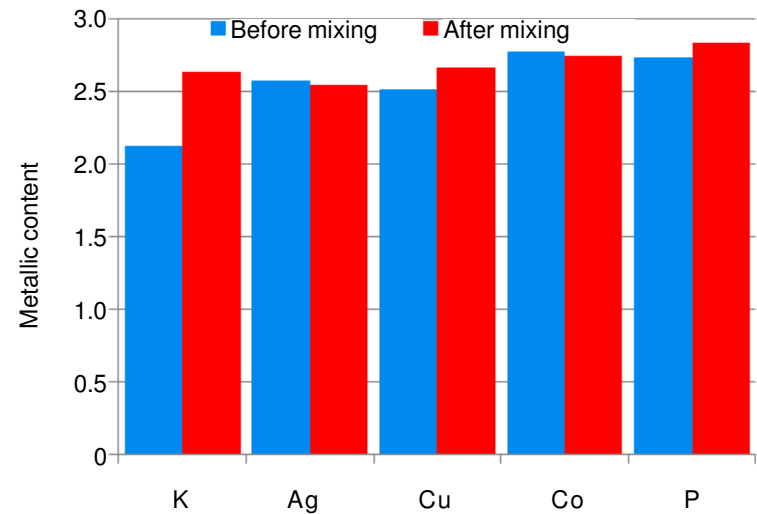

Fig. 11. Removal of $\mathrm{H}_{2} \mathrm{~S}$ for different samples; three nozzles before and after mixing

We used different metal treated activated carbon samples to remove the harmful gases (such as $\mathrm{NH}_{3}, \mathrm{H}_{2} \mathrm{~S}$ and $n$-butane). We find $\mathrm{Co}-\mathrm{AC}$ has the relatively best effect for remove harmful gases and after mixing the effect for remove harmful gases is enhanced. Illustrate with examples, for removal the $\mathrm{H}_{2} \mathrm{~S}$. Co-AC have 2.769 before mixing and 2.836 after mixing, it is bigger than any other samples. At the removal process of $\mathrm{H}_{2} \mathrm{~S}$, 
activated carbon as catalyst can catalyze $\mathrm{H}_{2} \mathrm{~S}$ oxidation and convert to elemental sulfur in the presence of oxygen ${ }^{29}$. It is also well known that impregnation of carbon with transition metal such as copper, molybdenum or chromium is the best way to lead to a good performance of activated carbon in the removal of harmful gas. Metal doped on activated carbon can increase the amount of $\mathrm{H}_{2} \mathrm{~S}$ adsorbed/oxidized on carbon ${ }^{30}$. Higher concentrations of metal may contribute to the much higher adsorption capacity compared to the other adsorbents. These results indicate that $\mathrm{H}_{2} \mathrm{~S}$ may be dominantly removed through the reaction with metal to produce metal sulfide ${ }^{31}$. Due to above reasons, metal-carbon has the good effect for remove harmful gas and this capability can enhance with increased the content of metal.

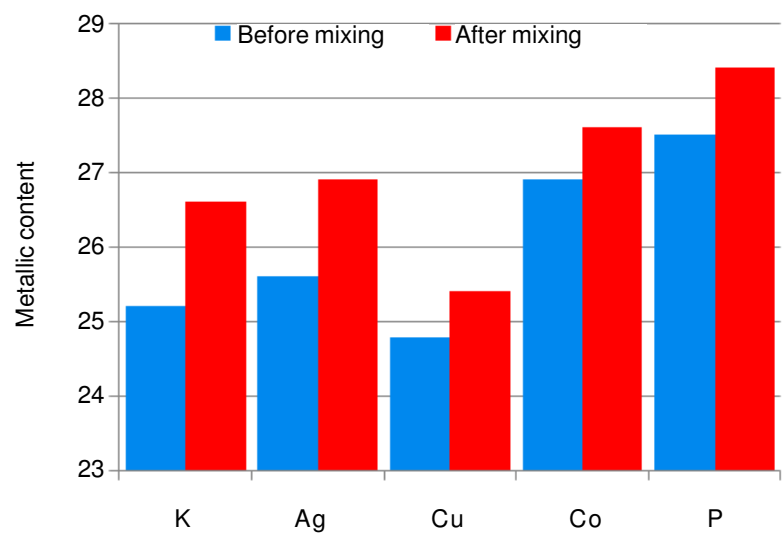

Fig. 12. Removal of $n$-butane for different samples and three nozzles before and after mixing

\section{Conclusion}

The results presented in this paper demonstrate that metalcarbon has the good effect for removal harmful gases and this capability can enhance with increased the content of metal. Used this novel method to mass production metal treated carbon is feasible plan. During the produce process, increased the nozzles the concentration of metal increased, we can control the concentration of metal by control the number of nozzle. This method is better than normal method. From the EDX results, the metal is uniform distribution on carbon particles, so this method can economize more reagents during the produce process. Compare the adsorption effect, the adsorption effect of samples is good and have better effect for removal gas.

\section{ACKNOWLEDGEMENTS}

This work was supported by the academic-industrial cooperation technique development support project supervised from the Small and Medium Business Administration in 2010. The authors are grateful to the Small and Medium Business Administration for financial support.

\section{REFERENCES}

1. X.Q. Wang, P. Ming, Y. Shi and M. Jiong, J. Hazard. Mater., 7, 588 (2009).

2. W.C. Oh, F.J. Zhang and M.L.Chen, J. Ind. Eng. Chem., 16, 299 (2010).

3. W.C. Oh, J. Photocatal. Sci., 1, 29 (2010).

4. E. Laperdrix, G. Costentin, O. Saur, J.C. Lavalley, C. N’edez, S. SavinPoncet and J. Nougayrede, J. Catal., 189, 63 (2000).

5. L.M.L. Leuch, A. Subrenat and P.L. Cloirec, Langmuir, 19, 10869 (2003).

6. V. Meeyoo and D.L. Trimm, J. Chem. Tech. Biotechnol., 68, 411 (1997).

7. J.J. Choi, M. Hirai and M. Shoda, Appl. Catal. A, 79, 241 (1991).

8. Y. Song, W.M. Qiao and S.H. Yoon, New Carbon Mater., 20, 294 (2005).

9. R.C. Bansal, J.B. Donnet and H.F. Stoeckli, In: Active Carbons, New York: Marcel Dekker, pp. 27-118 (1998).

10. H.P. Boehm and M. Voll, Carbon, 8, 227 (1970).

11. P. Davini, Fuel, 68, 145 (1989).

12. H. Tamai, Y. Kataoka, F. Nishiyama and H. Yasuda, Carbon, 38, 899 (2000).

13. O.C. Cariaso and P.L. Walker, Carbon, 13, 2330 (1975).

14. A. Primavera, A. Trovarelli, P. Andreussi and G. Dolcetti, Appl. Catal. A: Gen., 173, 185 (1998).

15. H. Katoh, I. Kuniyoshi, M. Hirai and M. Shoda, Appl. Catal. B, 6, 255 (1995).

16. A. Bagreev, H. Rahman and T.J. Bandosz, Adv. Environ. Res., 6, 303 (2002).

17. M.A. Daley, C.L. Mangun, J.A. DeBarr, S. Riha, A.A. Lizzio, G.L. Donnals and J. Economy, Carbon, 35, 411 (1997).

18. Y. Xiao, Q.Y. Liu, Z.Y. Liu, Z.G. Huang, Y.X. Guo and J.L. Yang, Appl. Catal. B: Environ., 82, 114 (2008).

19. P. Davini, Carbon, 39, 419 (2001).

20. J. Klinik and T. Grzybek, Fuel, 71, 1303 (1992).

21. P. Davini, Carbon, 39, 2173 (2001).

22. Z.P. Zhu, Z.Y. Liu, H.X. Niu and S.J. Liu, J. Catal., 187, 245 (1999).

23. Z. Hu, R.D. Williams, D. Tran, T.G. Spiro and S.M. Gorun, J. Am. Chem. Soc., 122, 3556 (2000).

24. G. Marban, R. Antuna and A.B. Fuertes, Appl. Catal. B, 41, 323 (2003).

25. M. Kobayashi and M. Flytzani-Stephanopoulos, Ind. Eng. Chem. Res., 41, 3115 (2002).

26. M.A. Belsa, A.J.G. Maroto and A.E. Regazzoni, J. Colloid Interf. Sci., 140, 287 (1990).

27. D. Nguyen-Thanh and T.J. Bandosz, J. Phys. Chem., 107, 5812 (2003).

28. T.J. Bandosz, J. Colloid Interf. Sci., 246, 1 (2002).

29. A. Oya, S. Yoshida, J. Alcaniz-Monge and A. Linares-Solano, Carbon, 33, 1085 (1995).

30. C. Moreno-Castilla, F.J. Maldonado-Hodar and A.F. Perez-Cadenas, Langmuir, 19, 5650 (2003).

31. X.Y. Guo, C. Bartholomew, W. Hecker and L.L. Baxter, Appl. Catal. B, 92, 30 (2009). 